\title{
REVIEW
}

\section{Aggressive and malignant pituitary tumours: state-of-the-art}

\author{
Dorota Dworakowska1,2,3 and Ashley B Grossman4,5 \\ 'Department of Hypertension and Diabetes, Medical University of Gdańsk, Gdańsk, Poland \\ 2Guys Richard Dimbleby Department of Cancer Research, Kings College London, London, UK \\ 3Endocard LTD, London, UK \\ ${ }^{4}$ Oxford Centre for Diabetes, Endocrinology and Metabolism, University of Oxford, Oxford, UK \\ ${ }^{5}$ Centre for Endocrinology, William Harvey Institute, Barts and the London School of Medicine, London, UK
}

Correspondence should be addressed to A B Grossman: ashley.grossman@ocdem.ox.ac.uk

\begin{abstract}
Pituitary adenomas are unique in multiple ways. They are rarely malignant in terms of metastases; yet, they may be aggressive. Their cancerous potential is defined in a classic oncological way by the ability to metastasise, and therefore, it has been crucial to differentiate this process from aggressive behaviour, characterised as a particularly invasive and/or recurrent behaviour and resistance to common modalities of therapy. Recently, however, important changes have been introduced to the diagnosis and management of aggressive and malignant pituitary tumours including the 4th edition of the World Health Organization (WHO) classification for endocrine tumours (2017) as well as ESE Clinical Guidelines (2018), although an attempt to establish predictive and/or prognostic markers of clinical aggressiveness remains difficult. In this review, we focus on a group of pituitary tumours causing significant problems in clinical practice and requiring multidisciplinary input. We summarise updates in definitions of tumour invasiveness, aggressiveness and malignant transformation, as well as histological classification, and emphasise the new considerations regarding aggressive and malignant potential and its relationship to therapeutic strategies.
\end{abstract}

Key Words
pituitary
- tumour
- aggressive
cancer
- carcinoma
temozolomide

\section{Introduction}

Pituitary tumours represent approximately $10-15 \%$ of intracranial tumours. Most of them are non-invasive, showing slow growth and remaining within the sella and/or displacing the surrounding tissues; however, up to $25-55 \%$ of pituitary adenomas (PAs) may show characteristics that are invasive and infiltrate surrounding structures, including the cavernous sinuses, bone, sphenoid sinuses, and, less commonly, nerve sheaths (Meij et al. 2002, Hansen et al. 2014). Pituitary carcinomas (PCs) are a rare clinical entity that represent only $0.1-0.2 \%$ of all pituitary tumours. Oncological malignant potential is defined by the ability to metastasise (including craniospinal and/or systemic metastases). Early identification of pituitary carcinoma is difficult yet remains crucial to appropriate management (Heaney 2014). While multiple reviews have addressed the molecular pathogenesis of pituitary tumours (Dworakowska \& Grossman 2009, Robertson \& Heaney 2016, Wierinckx et al. 2017), attempts at establishing predictive and/or prognostic markers of clinical aggressiveness remain largely unsuccessful and/or controversial. There have been recent consensus guidelines published (Raverot et al. 2018a), based in part on the new 
2017 World Health Organization (WHO) classification (Osamura et al. 2017a,b), and even suggestions that we abandon the term 'pituitary adenoma' entirely in terms of these all being pituitary neuroendocrine tumours (PitNETs) (Asa et al. 2017), with a variable propensity for invasion and malignancy, as for other NETs. We therefore feel it timely to consider the current state of play in this evolving field from our personal viewpoint.

\section{Diagnosis}

An attempt to improve the diagnostic process for aggressive pituitary tumours and PC was made in the newest European Society for Endocrinology (ESE) guidelines (Raverot et al. 2018a). The authors recommend the diagnosis of an aggressive pituitary tumour be considered in patients with a radiologically invasive tumour and unusually rapid tumour growth rate or clinically relevant tumour growth despite optimal standard therapies (surgery, radiotherapy and conventional medical treatments) (R 2.1.1). For quantification of tumour dimensions, invasion and growth, they suggested MRI in most instances ( $\mathrm{R}$ 2.1.2). Endocrine evaluation is required in all of these cases (R2.1.3) in patients with aggressive tumours, and either site-specific symptoms or discordant biochemical and radiological findings, screening for metastatic disease to diagnose PC is required ( $\mathrm{R}$ 2.1.4) (Raverot et al. 2018a). It would be beneficial if the future guidelines could help further as to when and how to assess malignancy in aggressive tumours. At present, the diagnosis of malignancy requires the presence of distant metastases, but this may be too limiting.

'Atypical' PAs were in the past defined as probably aggressive tumours, harbouring a Ki-67 (MIB-1) staining index of $3 \%$ or more, and positive immunohistochemical staining for p53 protein, according to the WHO classification in 2004 (Hirohata et al. 2014). The newest 4th edition of the WHO classification for tumours of endocrine glands as well as the newest ESE guidelines abandon the use of this term due to its poor reproducibility and low predictive value. There was a lack of evidence for the utility and predictive capacity of this classification (Lopes 2017, Mete \& Lopes 2017, Manojlovic-Gacic et al. 2018, Nishioka \& Inoshita 2018, Raverot et al. 2018a).

\section{Aggressiveness vs invasiveness}

The definition of aggressiveness for pituitary tumours has been rather confusing in the past, particularly as specific histopathological features appeared to be lacking.
However, aggressive pituitary tumours, which are intermediate in phenotype between PAs and PC, exhibit distinct clinical characteristics as they grow rapidly, frequently recur and are often resistant to conventional treatments (Colao et al. 2011). Nevertheless, the invasiveness of the pituitary tumour does not always correlate with aggressiveness. Invasive PAs show a variety of different pathological features and/or clinical course (Priola et al. 2017). Some of them display the histopathology of an adenoma with benign behaviour, even when invading the dura, bone or the surrounding anatomical structures. Furthermore, aggressiveness and invasiveness are interpreted differently by individual clinicians: these terms are often used interchangeably, whereas they are clearly different and describe differing characteristics with discordance in their predictive ability (Sav et al. 2015).

Some authors suggest that invasion of specific structures (e.g. the sphenoid bone or clivus) could serve as an indicative feature of aggressive behaviour (Heaney 2014), as most tumours demonstrating, for example, cavernous sinus invasion, may still show indolent behaviour and slow progression (Priola et al. 2017). In the historical Hardy's 'invasiveness' classification, only grade III (focal bone erosion) and grade IV (extensive bone erosion including skull base) tumours were considered as truly invasive (Handy 1969). In the extensively used Knosp classification, only grade III and IV adenomas (especially IIIB) are considered as truly invasive, classified on the basis of the extent of parasellar/cavernous sinus on imaging (Knosp et al. 1993, Di Ieva et al. 2014, Micko et al. 2015) (Fig. 1 and Table 1).

\section{Refractory tumours}

Some authors propose the use of the term 'refractory' pituitary adenoma for aggressive-invasive tumours exhibiting a distinctive disease course compared to benign adenomas or PCs. According to Dai et al., the 'refractory' pituitary adenoma demonstrated in their series a high Ki-67 index, rapid growth, frequent recurrence and resistance to conventional treatments and/or temozolomide (Dai et al. 2016). The specific criteria include proposed tumour infiltration of the adjacent structures based on radiological results or intraoperative findings. Dai et al. proposed not only to use the cut-off value of $>3 \%$ for Ki-67 but also included an increase in tumour growth velocity as $>2 \%$ per month. However, in most instances, it would be quite difficult to perform imaging so frequently. Another feature would be not only a failure to control tumour growth 

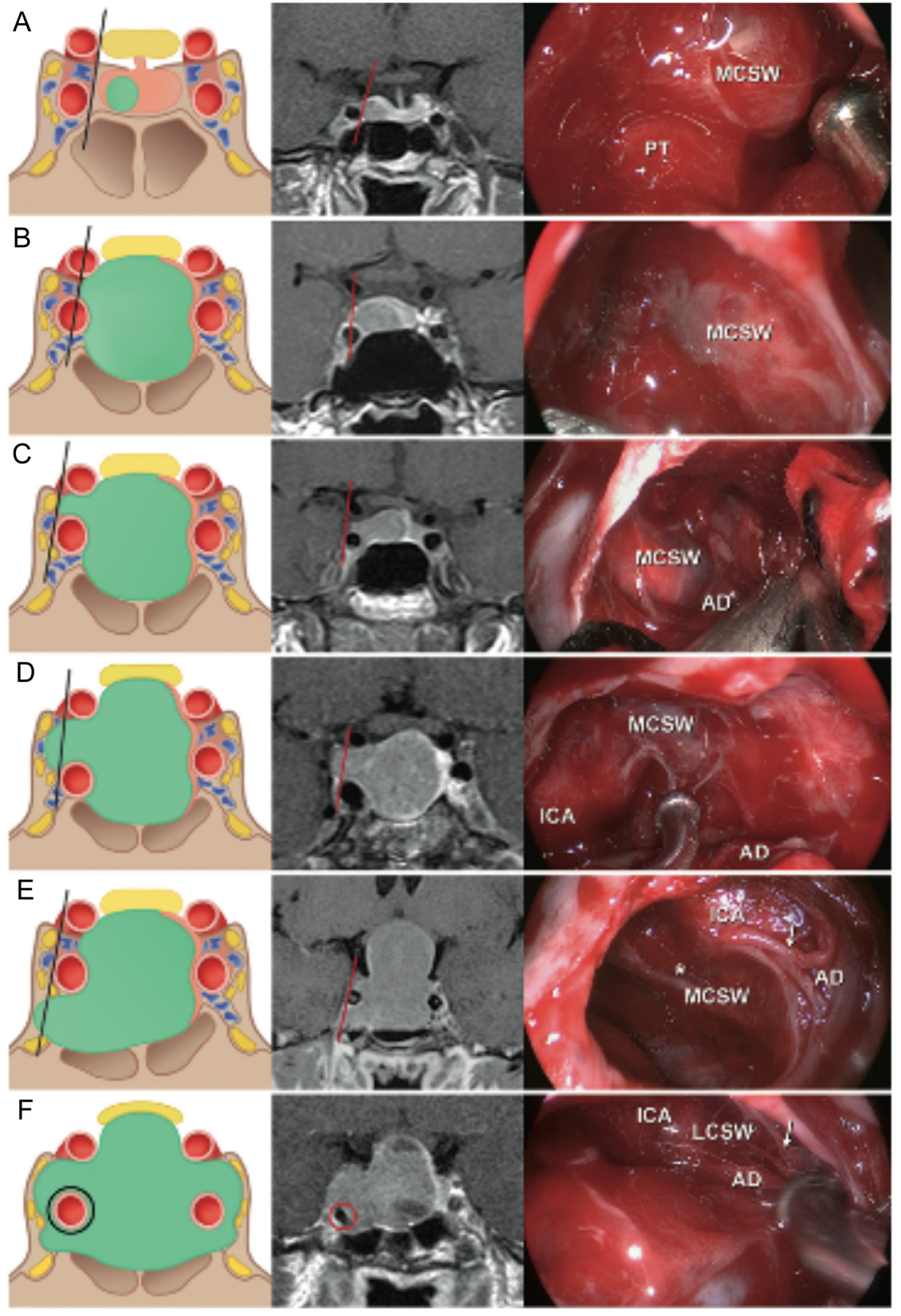

\section{Figure 1}

Graphic schemes (left), coronal MR images

(centre) and endoscopic views (right). (A) Grade 0: the adenoma does not encroach on the CS space. Thus, the tangent of the medial aspects of the intracavernous and supracavernous ICAs is not passed. (B) Grade 1: the medial tangent is passed, but the extension does not go beyond a line drawn between the cross-sectional centres of the intracavernous and supracavernous ICAs (the intercarotid line). (C) Grade 2: the tumour extends beyond the intercarotid line but not past the tangent on the lateral aspects of the intracavernous and supracavernous ICAs. (D) Grade 3A: the tumour extends lateral to the lateral tangent of the intracavernous and supracavernous ICAs into the superior CS compartment. (E) Grade 3B: the tumour extends lateral to the lateral tangent of the intracavernous and supracavernous ICAs into the inferior CS compartment. (F) Grade 4: there is total encasement of the intracavernous carotid artery. AD, adenoma; LCSW, lateral CS wall (seen after removing the medial CS wall); MCSW, medial CS wall; PT, pituitary gland. The asterisk indicates an invaded medial CS wall, and arrows indicate trabeculae. Reproduced with kind permission from Prof. Engelbert Knosp, Department of Neurosurgery, Medical University of Vienna, Vienna, Austria. Copyright $2015 \mathrm{E}$ Knosp.

and/or hormonal hypersecretion by current treatment modalities, but also the presence of tumour recurrence within 6 months after surgery (Dai et al. 2016).

\section{Endocrine oncology vs classical oncology}

There are several differences in the way we view pituitary tumours, especially malignant and aggressive ones. These discrepancies do not only differentiate such tumours from 'classical' oncology but are also quite heterogeneous in endocrine oncology itself. However, over the last few years, the pituitary community has changed its approach. PAs are no longer considered as a specific endocrine disease but rather as true tumours and cannot be readily divided into simply 'adenomas' vs 'carcinomas'. Similar to other NETs, all may be considered to have malignant potential, malignancy being defined as local invasiveness and recurrence, and resistance to therapy, with PCs just one end of the spectrum of PitNETs (Asa et al. 2017). This more oncological approach permits the appropriate use of chemotherapeutic drugs in some conditions and a better stratification and personalisation of the therapeutic options offered to patients (Lasolle \& Raverot 2016). 
Table 1 Systems for pituitary tumour invasiveness (Hardy 1969, Knosp et al. 1993, Micko et al. 2015).

\begin{tabular}{ll} 
Grade 0 & Knosp's classification of cavernous sinus invasion \\
Grade I & The adenoma does not pass the tangent of the medial aspects of the internal carotid artery (ICA) \\
The medial tangent is passed, but the extension does not go beyond the intercarotid line, which is the \\
line drawn between the cross-sectional centers of the intra- and supracavernous ICA \\
Tumour extends beyond the intercarotid line, but not beyond or tangent to the lateral aspects of the \\
intra- and supracavernous ICA \\
Grade III & Tumour extends laterally to the lateral tangent of the intra- and supracavernous ICA \\
Grade IV & Total encasement of the intracavernous carotid artery \\
Grade 0 & Intact with normal contour \\
Grade I & Intact with bulging floor \\
Grade II & Intact with enlarged fossa \\
Grade III & Localised sellar destruction \\
Grade IV & Diffuse sellar destruction \\
& Hardy's classification of supra- and parasellar extension \\
Grade A & Symmetrical suprasellar extension \\
Grade B & Suprasellar cistern only \\
Grade C & Recess of the third ventricle \\
Grade D & Whole anterior third ventricle \\
Grade E & Asymmetrical parasellar extension \\
\hline
\end{tabular}

The classical understanding of the predictive factors relate to their value of prediction in response to particular treatments, whereas prognostic factors influence patient survival (overall-, disease-free or progression-free survival). These terms are used in endocrine oncology in a 'liberal' and promiscuous manner, which renders analysis difficult when comparing different sets of results.

Similar complexity comes with the interpretation of statistical analyses. In classical oncology, significance in univariate analysis of a certain marker needs to be confirmed in multivariate analysis (where several features are analysed and considered simultaneously) to become an independent prognostic factor. The number of cases included to analysis affects the quality and strength of the results. Inclusion of such multiple factors makes the analysis of results in series of rare tumours very difficult. One such example comes from a study by Zaidi et al. (2016) where clinically aggressive lesions (in comparison to non-aggressive) were more likely on univariate analysis to have a larger axial diameter on MRI $(2.9 \pm 1.9 \mathrm{~cm}$ vs $1.9 \pm 0.7 \mathrm{~cm}, P=0.02)$, greater incidence of cavernous sinus invasion $(65.2 \%$ vs $20.8 \%, P<0.01)$ and greater incidence of clival extension $(60.9 \%$ vs $0, P<0.01)$ on preoperative imaging. On multivariate analysis, however, only the Ki-67 proliferative index trended towards statistical significance $(P=0.06)$ (Zaidi et al. 2016). In that study, tumours were defined as clinically aggressive if they required additional therapeutic intervention following first surgery, including further surgery, medical therapy or radiosurgery, but in fact, of the total cohort of 569 tumours, only 23/569 were noted to have a clinically aggressive course (according to the authors' broad definition of aggressiveness) (Zaidi et al. 2016), challenging the statistical significance of their findings. In another study, multivariate analysis revealed that Ki-67 was the only factor that positively correlated with tumour size and recurrence, with staining for the factors PTTG1 and FGFR4 having no independent effect (Ramirez et al. 2012).

\section{p53 tumour suppressor protein}

p53 protein is a product of the tumour suppressor gene playing a role in apoptosis, inhibition of angiogenesis and genomic stability. The prognostic value of its expression has been previously assessed in many cancers (Dworakowska et al. 2009a). Physiologic levels of p53 typically are not detectable by immunohistochemistry due to the short half-life of WT p53: some mutations of the P53 gene may result in p53 protein nuclear accumulation (due to extension of its half-life), allowing for its immunohistochemical detection.

The reliability of p53 as a marker of clinical invasiveness in pituitary tumours is still a subject of debate (Pernicone et al. 1997, Scheithauer et al. 2005, Heaney 2011, Zaidi et al. 2016, Lopes 2017). Ozer et al. found that of 41 PAs, p53 expression was significantly increased in recurrent tumours ( $P=0.002)$ (Ozer et al. 2003). Thapar et al. reported that in 70 PAs and 7 PCs, p53 expression, when conclusively present, may also be of diagnostic utility as a marker of biologically aggressive behaviour (Thapar et al. 1996b). 
Trouillas et al. proposed a prognostic clinicopathological classification of PAs (including assessment of p53) based on a multicentre case-control study of 410 patients with 8 years of post-operative follow-up (Trouillas et al. 2013). The classification was validated subsequently in different cohort, demonstrating the prognostic value of p53 (Raverot et al. 2017). Contradictory studies have indicated that p53 is an inadequate marker for tumour aggressiveness and behaviour and that the p53 protein detected by immunohistochemistry is actually a WT form and thus unrelated to pituitary tumour invasiveness $(P=0.71)$ (Suliman et al. 2001, Zaidi et al. 2016). For this reason, the new WHO classification advises that it is not a useful marker for aggressiveness for routine use, although in some circumstances, it may aid in decision making (Osamura et al. 2017a,b, Nishioka \& Inoshita 2018).

\section{Tumour proliferation}

The MIB-1 labelling index (LI) stains for the Ki-67 antigen and is associated with cell proliferation. Recent work has demonstrated that it acts as a surfactant to separate chromosomes during mitosis, and is thus a marker of cell division (Cuylen et al. 2016). It is upregulated in dividing cells and involved in ribosomal RNA transcription. Since the initial description of Ki-67 in PAs by Burger et al. (1986), multiple researchers have attempted to correlate its value with clinicopathological parameters and its predictive and prognostic value (Salehi et al. 2009, Heaney 2011, 2014, Zaidi et al. 2016, Raverot et al. 2018a), much as has been achieved with NETs (Kloppel 2017, Panzuto et al. 2017). Thapar et al. reviewed the Ki-67 index in 77 PAs and carcinomas and suggested that the cut-off value of 3\% distinguishes invasive from non-invasive adenomas with $97 \%$ specificity and $73 \%$ sensitivity (Thapar et al. 1996a); this cut-off was therefore adopted in the previous WHO criteria in 2004. However, several groups have demonstrated conflicting results, either supporting the use of this marker as a predictor of pituitary tumour recurrence or arguing against its utility (Zaidi et al. 2016). Salehi et al. considered that the contradictory reports on the role of the Ki-67 index are most probably the result of the variation in the definition of recurrence as well as the differing techniques of Ki-67 immunohistochemistry (Salehi et al. 2009).

In spite of these discordant conclusions, to help inform potential predictors of tumours aggressiveness in pituitary tumours, the ESE guidelines recommend histopathological analysis, which should include as a minimum immunodetection of pituitary hormones and
Ki-67 proliferative index evaluation. They also recommend p53 immunodetection and the evaluation of the mitotic count when the Ki-67 index is $\geq 3 \%$ (R 2.2.1) (Lopes 2017, Raverot et al. 2018a). The ESE recommendations also suggest that interpretation of histopathological results should be in the clinical, radiological and surgical context of the individual patient, with the particular caveat that no marker alone is sufficient to predict tumour behaviour (R 2.2.2) (Raverot et al. 2018a).

\section{Histology}

The WHO classification of tumours of endocrine organs was revised in 2017 (4th edition) (Nishioka \& Inoshita 2018). This new classification has been reviewed in several updated and very comprehensive papers (Lopes 2017, Mete \& Lopes 2017, Manojlovic-Gacic et al. 2018, Nishioka \& Inoshita 2018). According to recent knowledge on tumour development and prognosis, important changes in the new classification of PAs were introduced (Lopes 2017, Osamura et al. 2017a,b). The new classification focuses on adeno-hypophyseal-cell lineage for the designation of a pituitary adenoma. Based on this classification, assessment of pituitary transcription factors is also recommended to complement an accurate diagnosis, especially in hormone-negative tumours. Subsequently, based on this revision, null cell adenomas have been shown to be extremely rare, as ultrasensitive techniques have shown that the majority of previously reported 'null cell' adenomas are in fact gonadotrophic in origin (Nishioka \& Inoshita 2018).

There are three major pathways of adeno-hypophyseal cell differentiation and relevant transcription factors: corticotrophs (demonstrable by the T-box pituitary transcription factor (T-pit)), somatotrophs/lactotrophs/ mammosomatotrophs/thyrotrophs (demonstrable by pituitary transcription factor 1 (Pit-1)), and gonadotrophs (demonstrable by steroidogenic factor-1 (SF-1) and/or GATA-2 in the presence of estrogen receptor- $\alpha(E R \alpha))$. At present, however, there are still no reliable commercial antibodies for T-pit (Fig. 2) (Nishioka \& Inoshita 2018).

As noted above, the 4th edition of the WHO classification recommended assessment of tumour proliferation markers and other clinical/radiological parameters such as invasion to predict aggressiveness. According to this classification, 'high-risk adenomas' were characterised as those with rapid growth, radiological invasion and a high Ki-67 proliferation index. This classification does emphasise recognition of adenomas which are 'special variants' known for more aggressive 


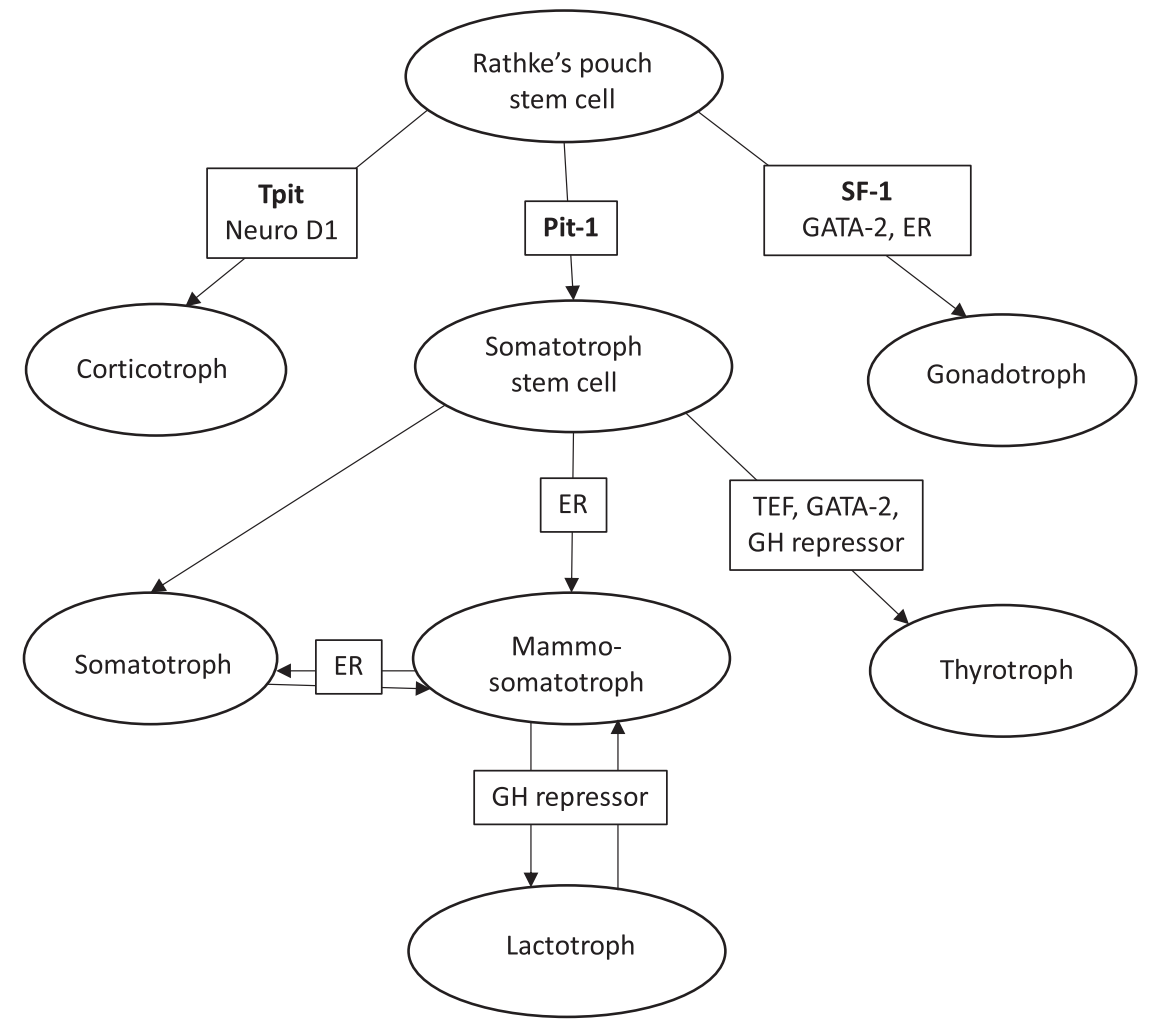

\section{Figure 2}

Adenohypophysial cell lineage and the transcription factors. Corticotroph are determined by T-pit and neuro D1; gonadotrophs are determined SF-1, GATA-2 and ER; Somato-, Lacto- and Thyrotroph are determined by Pit-1 (Nishioka \& Inoshita 2018). behaviour with a higher probability of recurrence, regardless of histological grading, which include sparsely granulated somatotroph adenomas, pluri-hormonal PIT-1-positive adenomas, silent corticotroph adenomas, lactotroph adenomas in men and Crooke cell adenomas (Lopes 2017, Mete \& Lopes 2017). Furthermore, silent corticotroph tumours also tend to exhibit aggressive clinical features including local invasion (cavernous sinus, sphenoid sinus and bone), apoplexy and recurrence (Webb et al. 2003, Heaney 2011, Jahangiri et al. 2013, Mete et al. 2013, Heaney 2014, Xu et al. 2014, Cooper 2015). Nelson's syndrome (occurring after removal of cortisol-mediated negative feedback following bilateral adrenalectomy in Cushing's disease) is also associated with a propensity to increased pituitary tumour growth and progression to metastasis (Kaltsas et al. 2005, Heaney 2014).

Crooke cell adenomas are aggressive corticotrophic pituitary tumours: they are commonly invasive, recurrent and may progress to a carcinoma (Heaney 2011, 2014). One case series of 31 patients with Crooke cell adenoma showed $60 \%$ of cases with recurrence, $24 \%$ with multiple recurrences and two patients progressing to metastases (George et al. 2003).

Immunohistochemical staining for T-PIT staining has made possible the identification of hormone-immunonegative adenomas, which show differentiation towards the corticotroph lineage and which may help to identify more aggressive tumours (with a clinical behaviour similar to silent corticotroph adenomas) (Lopes 2017).

\section{Tumour functionality and other clinicopathological features}

Oncological potential differs in varying subtypes of PAs. In a study by Lv et al. (2018), clinically aggressive lesions $(N=26)$ were more likely to be functional $(46.2 \%$ vs $17.4 \%, P=0.0388)$ and be detected in males $(65.4 \%$ vs $21.7 \%, P=0.0037)$. Clinically aggressive adenomas had a higher Ki-67 index (5.0 (5.3)\% vs 4.1 (1.3)\%, $P=0.0011$ ) and presented with larger tumours $\left(11.83(11.95) \mathrm{cm}^{3}\right.$ vs $\left.5.39(6.08) \mathrm{cm}^{3}, P=0.0174\right)$. The importance of the functional status as an independent predictor of clinical aggressiveness was confirmed in a multivariate analysis $(P=0.009)$ along with gender $(P=0.017)$ and the Ki-67 index $(P=0.024)$ : a Ki-67 index of more than $4.45 \%$ was associated with a shorter progression-free survival. Nonfunctioning pituitary adenomas (NFPAs) do not cause endocrine symptoms related to hypersecretion of adenohypophyseal hormones and are clinically characterised by symptoms due to a growing sellar tumour mass. 
Histopathological classification of this tumour group has always been challenging due to their heterogeneity, limited knowledge of their biology and diverse methodological problems (Manojlovic-Gacic et al. 2018, Raverot et al. 2018b).

Ceccato et al. reported recently a series of a homogeneous consecutive cohort of PAs $(N=100)$. Patients with NFPAs were older than those with functioning tumours, and the diagnosis might be delayed until mass symptoms occur as they lacked symptoms related to hormonal hypersecretion. They reported that the characteristics of aggressiveness were similar between silent adenomas and NFPAs, even separately analysing silent corticotrophinomas and gonadotrophinomas (Ceccato et al. 2018).

In a study by Ogawa et al. (2018), the clinical characteristics and mid-term prognosis of patients with NFPAs with a high proliferative potential were retrospectively investigated. This study identified 53/845 NFPA patients with a Ki-67 LI of $>3 \%$ (6.3\% of the total), initially treated by surgery. In that cohort, no prophylactic treatment was used for patients with residual tumour, but salvage therapy was given for tumour progression. Comparison of gross total removal $(n=22)$ and non-total removal $(n=31)$ groups showed a significantly longer progression-free period in the former group $(P<0.001)$. As salvage treatment, gamma knife radiosurgery was used resulting in 10/11 patients remaining progression free. Fractionated irradiation was given to ten patients, resulting in two patients remaining progression free; deaths occurred in five patients including three of transformation to pituitary carcinoma, dementia was seen in one patient caused by frontal lobe dysfunction and progression reported in two patients requiring additional surgery and gamma knife radiosurgery. Temozolomide was administered to two patients, resulting in deaths in both patients including one transformation to a pituitary carcinoma. The authors concluded that a good prognosis in NFPAs with high proliferative potential can be expected where there is total removal of the tumour, with gammaknife radiosurgery used as a salvage treatment. However, this therapy is limited to residual tumour, which is distant from optic pathways, and the poor results from standard radiation therapy are surprising. In a large and more recent series, recurrent NFPAs which subsequently received standard external beam radiotherapy showed a lower recurrence rate than those observed or who were treated by surgery alone, so it may be that the efficacy of radiotherapy is contingent on the centre as much as on the specific type (Tampourlou et al. 2017).
It should also be emphasised that 'functionality' is a relative concept: some tumours may be truly secretory and cause a significant functional syndrome, while some (in effect, very few) may show no functionality and completely negative immunostaining for any pituitary hormone or transcription factor. In fact, many tumours may show transcription factor positivity and even hormone immunostaining without a functional syndrome, 'silent tumours', while others may show mild biochemical abnormalities, possibly referred to as 'whispering tumours'. Thus, there is actually a spectrum of functionality in practice (Drummond 2018).

\section{Progression and malignant transformation}

The malignant transformation of a 'benign' pituitary adenoma has always been a matter of controversy, and the progression from benign to aggressive/malignant character poorly understood. PCs are thought to arise either de novo, or more frequently, from a malignant transformation of a pre-existing 'benign' adenoma (Lopes et al. 2005, Scheithauer et al. 2005, Sbardella et al. 2016). Highly aggressive transformation, including that to a carcinoma, is rare, and mainly occurs in prolactin- and ACTH-secreting tumours, possibly because these tumours are less likely to show markers of senescence, compared with those of other adenoma types (Alexandraki et al. 2012). It is unclear what proportion of these aggressive adenomas will progress into carcinomas, and most importantly, how to predict when this is likely (Pernicone et al. 1997, Ragel \& Couldwell 2004, Mete \& Lopes 2017). When non-compliance is ruled out, escape from the control by initial medical therapies (as reported in prolactin-producing adenomas) may be associated with de-differentiation of the tumour and thus the potential for malignant transformation (Sbardella et al. 2016).

Several case reports suggest that the latency between the first presentation of a pituitary adenoma and its transformation to a carcinoma depends on the type of endocrine function of the tumour: the average latency period for ACTH-secreting carcinomas was reported as 9.5 years and for prolactin-secreting carcinomas as 4.7 years (Yang et al. 2016).

The mechanism of invasion seems to be similar to other malignancies as it is based on the ability to freely pass through the extracellular matrix and vascular endothelium, an epithelial-mesenchymal transition, spreading by the bloodstream with some evidence suggesting a possible role for deregulation of gene expression (Gurlek et al. 2007). Having said that, 
the mechanisms underlying the metastatic activity of PCs remain unclear, and the variation of gene expression in the primary is not always concordant in the metastases (Pei et al. 1994).

The matter becomes more complicated if we try to assess the role of previous radiotherapy in malignant transformation. Radiation has been reported to be implicated in the development of fibrosarcoma, but may also induce malignant changes in PAs (Casson et al. 1986, Tanaka et al. 2013). Tanaka et al. presented a case report showing cerebro-spinal metastases after radiation and gamma-knife treatment, suspecting that repeated radiation therapy for the pituitary and intracranial tumours may induce malignant transformation and the multiple spinal metastases (Tanaka et al. 2013). However, this concept is very difficult to prove, as aggressive tumours are more likely to be irradiated and such a correlation does not prove cause and effect.

An unusual case presented by Krueger et al. complicates the matter even further (Krueger \& Seibly 2017). They reported a 52-year-old man who had a pituitary adenoma removed via a craniotomy. The tumour recurred 3 years post-operatively near the surgical tract, and slowly enlarged before removal 2 years later. Technically, this lesion could be defined as a pituitary carcinoma; however, the origin of the secondary mass(es) in this case is quite unclear, with similar histology in the second mass compared to that initially removed (Krueger \& Seibly 2017). While this patient received CyberKnife therapy for a residual mass following the initial surgery, there is no evidence to support radiation-induced PAs specifically (Minniti et al. 2005), and it remains possible that there was iatrogenic seeding along the surgical tract (Taylor et al. 1994). Tanaka et al. described a case of a patient who developed multiple supra-tentorial, cerebellar and cervical spine dural metastases 13 years after initial surgical operation for a pituitary adenoma (Tanaka et al. 2013). Thus, even apparently benign adenomas require long-term follow-up (Krueger \& Seibly 2017).

However, while the majority of aggressive pituitary tumours require multiple operations as well as radiation therapy, it seems (albeit on evidence which is incomplete at present) that therapeutic modalities of surgery and radiation are unlikely to be major mediators of malignant transformation (Tanaka et al. 2013).

The incidence of distant metastases is very high in corticotroph carcinomas when compared with other PCs (Tanaka et al. 2013): 71\% and 57\% of ACTH- and prolactin-secreting PCs, respectively, showed systemic dissemination rather than presenting with intracranial metastases (Pernicone et al. 1997). Somatotroph tumours are rarely malignant, and distant metastases exceedingly rare. However, Taya et al. described a patient with GH-producing adenoma with intracranial dissemination, requiring surgery 7 years after initial trans-sphenoidal surgery for a pituitary 'adenoma' (Taya et al. 2004). Endo et al. reported a case of a 66-year-old woman with a malignant transformation of an ectopic GH-producing pituitary tumour, which was mainly located in the clivus. The initial presentation included left oculomotor and abducens nerve palsies, clearly a feature of aggressiveness. The initial histology following surgery revealed tumour cells with slightly irregular nuclei but without mitoses. Interestingly, even though the Ki-67 was $8.7 \%$, p53 immunohistochemistry was negative. This tumour acutely enlarged causing a subarachnoid haemorrhage only 2 months after the initial operation. Pathologic findings of the second surgical specimen showed a significant change in tumour histology including significant nuclear atypia, an increase in Ki-67 to $27.7 \%$ and positive p53 staining and a loss of the previous GH immunopositivity (Endo et al. 2018). Lenders and McCormack recently reported malignant transformation in NFPAs (Lenders \& McCormack 2018).

\section{Pituitary carcinomas}

Pituitary carcinoma is a rare disease with high mortality rate: its low incidence results in a diagnostic and therapeutic challenge. Based on the 2004 WHO classification, pituitary tumours were previously divided into typical, atypical and carcinoma. As noted earlier, current WHO criteria have abandoned grading tumours as 'atypical' due to its limited prognostic value (Lopes 2017, Mete \& Lopes 2017).

The diagnosis of a pituitary carcinoma is often preceded by the presence of unusual symptoms such as hearing loss, ataxia, motor impairment or a neck mass, prompting further diagnostic testing (Kaltsas et al. 2005). Metastases rarely dominate the clinical picture in the early stages of disease and, at times, cases are only discovered post mortem (Petterson et al. 1992, Stewart et al. 1992, Kemink et al. 1999, Kaltsas et al. 2005). Early identification of pituitary tumours at risk for progression to pituitary carcinoma is difficult, and no combination of histopathological or immunohistochemical analyses has conclusively been able to identify PAs that will progress to carcinoma. Suspicion should be raised when patients present with tumours of aggressive subtypes and histological features and with multiple recurrences. 
Prior to an analysis published by Yoo et al. (2018), there had been no large-scale clinical trials or retrospective analyses of large patient samples. The analysis of published PCs indicate high mortality rates of $66 \%$ at 1 year and nearly $80 \%$ within 8 years after diagnosis of PC, despite aggressive therapies (Pernicone et al. 1997, Ragel \& Couldwell 2004). In the review by the Yoo et al. 69 studies were included, with 72 unique cases, showing that the PCs were more common in males in comparison to females (55.6 vs $44.4 \%$, respectively). The average age at diagnosis was 46.3 years. Corticotroph tumours were most common $(34.7 \%)$, followed by prolactinomas $(23.6 \%)$ and null cell tumours (15.3\%). The average latency period from pituitary tumour diagnosis to metastasis was 9 years. The patients underwent surgical therapy $(100 \%$ with an average of 2.76 procedures), radiotherapy ( $84.7 \%$ of cases) and chemotherapy (33.3\%, with temozolomide in $22.2 \%)$. The mortality rate was $54.8 \%$ with average time to death after diagnosis of approximately just 10 months (Yoo et al. 2018).

In the analysis performed by Yoo et al., the metastases in PC were intracranial or spinal, 43.1 and 37.5\%, respectively. Liver metastases were seen in $13.9 \%$. Cervical lymph node and bone metastases were seen in $11.1 \%$ and 9.7\% of PC cases, respectively. Central nervous system metastasis was found in $58.3 \%$, systemic metastasis in $31.9 \%$, and both central nervous system and systemic metastasis identified in $8.3 \%$ of cases (Yoo et al. 2018). However, Pernicone et al. reported previously that $71 \%$ and $57 \%$ of ACTH- and prolactin-secreting PCs, respectively, reported systemic dissemination rather than presenting with intracranial metastases (Pernicone et al. 1997).

\section{Molecular biology}

Our limited understanding of the molecular pathogenesis of pituitary tumours and the malignant transformation to PC does not help in the development of the new therapeutic strategies or increase the efficacy of current ones. Many previous reviews have demonstrated genes promoting malignant transformation, angiogenesis, invasion, metastasis and recurrence. Although most of these genes and proteins have not been fully analysed with regard to their downstream mechanisms, diagnostic or therapeutic application, and they at least have the potential to become candidate PC biomarkers and/or molecular targets for guiding personalised treatment (Dworakowska \& Grossman 2012, Yang et al. 2016).

Pituitary carcinomas rarely occur in genetic syndromes: examples of PC patients with MEN1 mutations have been documented (Scheithauer et al. 2005, 2009, Gordon et al. 2007), while AIP, PRKAR1A, DICER1 and GPR101 mutations have not been associated with metastatic spread to date (Tufton et al. 2017), although there is one report of a PC in a patients with an $S D H-B$ germline mutation (Tufton et al. 2017). A comprehensive review has been recently been published by Yang et al. (2016) showing a clear correlation with tumour cell cycle progression, angiogenesis, metastases, invasion and upregulation of cyclin D1, VEGF, MMP-9, miRNAs and p21Cip1, possibly contributing to malignant transformation of adenomas to PCs. The group also showed that downregulated factors including MGMT, p16Ink4A, p27Kip1, Bcl-2, Bax, Bcl-x and MT3 were involved in the cell cycle, apoptosis, tumour suppression, metabolism and enhanced TMZ sensitivity (Yang et al. 2016).

The co-occurrence of PAs and paragangliomas is a rare event. Such association was first described in 1952 (Iversen 1952), but it is only recently that the underlying genetic mutations have been elucidated in some of these cases (Tufton et al. 2017). Mutations in one of the five succinate dehydrogenase (SDHA-D, SDHA2F) genes are the most common, followed by mutations in MEN1 and RET (Gill et al. 2014, Denes et al. 2015). SDH mutation-related pituitary tumours have a more aggressive phenotype than is commonly seen in sporadic tumours. PAs occurring in patients with $S D H$ mutations or adenomas bearing somatic mutations are more often prolactinomas followed by gonadotroph adenomas and somatotroph tumours (Denes et al. 2015). A case of a pituitary carcinoma occurring in a patient with a succinate dehydrogenase subunit B $(S D H B)$ mutation and history of paraganglioma has been reported, as noted earlier (Tufton et al. 2017).

Subtype III PAs, now known as 'pluri-hormonal Pit-1 positive adenomas', are clinically non-functional adenomas that are more invasive and recur more often than conventional null cell tumours. Richardson et al. showed that their specific feature is an enlarged and fragmented Golgi apparatus, as detected by immunohistochemistry. They subsequently performed whole-transcriptome sequencing (RNAseq) and quantitative RT-PCR on four such tumours and four conventional null cell adenomas: the genes that were highly upregulated in all the plurihormonal Pit-1-positive tumours included two secreted proteins involved in the suppression of T-lymphocyte activity, i.e., $A R G 2$ and SEMA3A. Highly downregulated genes in all these adenomas included $H L A-B$, suggesting reduced antigen presentation by the adenoma to cytotoxic T-cells: they also found a relative decrease in the overall concentration of T-lymphocytes. These results suggest 
that pluri-hormonal Pit-1-positive adenomas actively suppress the immune system and raise the possibility that they may be treatable with immune checkpoint inhibitors or nonspecific cancer immunotherapies (Richardson et al. 2017).

\section{Genetic screening}

The ESE guidelines indicate the need for the germline genetic testing based on young age at presentation or family history of pituitary or endocrine neoplasia, as recommended for patients with non-aggressive pituitary tumours (R 2.2.3). Even though these recommendations are useful, the quality of evidence behind them was classified as very low (+000) (Raverot et al. 2018a).

\section{ESE guidelines summary}

The ESE guideline provides clinical guidance on diagnosis, treatment and follow-up in aggressive pituitary tumours and carcinomas (Raverot et al. 2018a). The authors systematically reviewed the literature according to the GRADE (Grading of Recommendations Assessment, Development and Evaluation) system. Raverot et al. included to their analysis 14 single-arm cohort studies (total number of patients $=116$ ) with first- and secondline treatment for aggressive pituitary tumours and PCs, of whom most were treated with temozolomide $(n=11$ studies, total number of patients $=106$ ). In this review, temozolomide resulted in a positive treatment effect in nearly half of the patients (47\%; 95\% CI: $36-58 \%)$. The guideline was additionally supported by the data coming from an ESE survey on aggressive tumours (165 patients) (McCormack et al. 2018). The ESE recommended that patients with aggressive tumours or carcinomas should be discussed and managed by expert multidisciplinary teams (endocrinologist, neurosurgeon, pituitary pathologist, neuro-radiologist, radiation oncologist, medical oncologist, $\mathrm{R}$ 1.1.1). They recommend that surgery should be performed by a neurosurgeon with extensive experience in pituitary surgery and further discussion with an expert neurosurgeon regarding repeat surgery prior to consideration of other treatment options (R3.1.1 and R3.1.2, respectively with the quality of the evidence behind these recommendations classified as low (++00) (Raverot et al. 2018a). They recommend standard medical treatment with maximally tolerated doses in order to control tumour growth (R 3.3.1). Current reviews on the medical therapy of pituitary tumours summarised all the agents available these days to treat functioning tumours (Langlois et al. 2017). In non-functioning tumours, radiotherapy was recommended in cases with clinically relevant tumour growth despite surgery, whereas for functioning tumours, it was recommended after surgery and standard medical treatment ( $\mathrm{R}$ 3.2.1, $++00)$. Adjuvant radiotherapy should be considered in cases with clinically relevant invasive tumour remnant with pathological markers (Ki-67 index, mitotic count, p53 immunodetection) strongly indicating aggressive behaviour (R 3.2.2, +000). The different radiotherapy options (taking into consideration tumour size and location, pathology) should be discussed prior to treatment with an expert radiation oncologist ( $\mathrm{R}$ 3.2.3). Lastly, the guidelines provide information about the follow-up, which for aggressive tumours should be lifelong ( $\mathrm{R} 4.3,++00$ ). Monitoring requires both radiological and biochemical evaluation; MRI (in most instances) to be performed every 3-12 months, guided by prior tumour growth rate and/or location of tumour (proximity to vital structures) $(\mathrm{R} 4.1,+000)$, whereas repeat full endocrine evaluation should be performed every 3-12 months as guided by the clinical context (R 4.2, +000).

A review by Trouillas et al. complemented the ESE survey, commenting in detail on some clinicopathological findings, specifically differentiating aggressive tumours from carcinomas (Table 2) (Trouillas et al. 2018). The authors underlined that given that the diagnosis of a malignant pituitary tumour remains difficult, and aggressive tumours and true carcinomas alike result in premature death as a result of tumour progression, they propose that an aggressive tumour should be considered a tumour with malignant potential (Table 3) (Trouillas et al. 2018). This was appropriately followed by a consensus view that all pituitary tumours should be considered as pituitary neuroendocrine tumours (PitNETs), as NETs elsewhere are generally assumed to have malignant potential (Asa et al. 2017).

Table 2 Similarities between the 125 aggressive pituitary tumours (APT) and 40 pituitary carcinomas (PC): modified from the diagram by Trouillas et al. (2018).

\begin{tabular}{|c|c|c|c|c|c|}
\hline & Gender (\%) & Tumour type (\%) & $\begin{array}{l}\mathbf{K i}-67 \\
\geq 3 \%\end{array}$ & $\begin{array}{c}\text { p53 } \\
\text { IHC (\%) }\end{array}$ & Mortality (\%) \\
\hline $\mathrm{APT}$ & Male 65 & $\begin{array}{l}\text { Corticotroph } \\
45\end{array}$ & 81 & 73 & 28 \\
\hline$P C$ & Male 63 & $\begin{array}{l}\text { Corticotroph } \\
48\end{array}$ & 85 & 78 & 43 \\
\hline
\end{tabular}


Table 3 Potential pituitary neuro-endocrine tumour (PitNET) behaviours: modified from the diagram by Trouillas et al. (2018).

\begin{tabular}{|c|c|c|c|c|c|c|}
\hline MRI & Pathology & Grade & $\begin{array}{l}\text { Surgery and/or } \\
\text { medical treatment }\end{array}$ & $\pm \mathbf{R T}$ & TZM & Clinical classification \\
\hline \multirow[t]{2}{*}{ Non-invasive (60-65\%)* } & Non-proliferative & $1 a$ & Cured & $\mathrm{n} / \mathrm{a}$ & $\mathrm{n} / \mathrm{a}$ & Adenoma \\
\hline & Proliferative & $1 b$ & Cured or remission & $\mathrm{n} / \mathrm{a}$ & $\mathrm{n} / \mathrm{a}$ & \\
\hline \multirow[t]{3}{*}{ Invasive $(35-40 \%)$ * } & Non-proliferative & $2 a$ & Persistent disease & Controlled & $\mathrm{n} / \mathrm{a}$ & Invasive PitNET \\
\hline & Proliferative & $2 \mathrm{~b}(10 \%) *$ & Persistent disease & $\begin{array}{l}\text { Recurrence } \\
\text { Progression }\end{array}$ & Yes & $\begin{array}{l}\text { APT: invasive PitNET with } \\
\text { malignant potential }\end{array}$ \\
\hline & & 3 & Persistent disease & Metastasis & Yes & $P C(0.2 \%) *$ \\
\hline
\end{tabular}

*Frequencies from the surgical series.

APT, aggressive pituitary tumour; MRI, magnetic resonance imaging; PC, pituitary cancer; RT, radiotherapy; TZM, temozolomide.

\section{Temozolomide}

Temozolomide (TMZ) is an oral alkylating drug, which has become a promising treatment option for aggressive tumours and carcinomas. An update on its use has very recently been summarised by Syro et al. (2018), and we therefore simply underline the most important facts. TZM has been demonstrated to cause not only shrinkage of pituitary tumours but also a normalisation of hormone hypersecretion in many instances. It has thus formed an important part of the armamentarium of therapies for aggressive tumours, particularly in view of its relatively high tolerability and freedom from adverse effects (Raverot et al. 2018a). However, its role in the sequencing of therapy remains unclear, and there is no doubt that in many cases improvements are temporary and recurrence/ regrowth frequent (Hirohata et al. 2014, Lasolle et al. 2017, McCormack et al. 2018).

TMZ is available in an oral form, and its ability to cross the blood-brain barrier makes it superior to other chemotherapy drugs (Losa et al. 2016). It acts through methylation of the $\mathrm{O} 6$ position of guanine in DNA to form a potent cytotoxic DNA adduct, which causes a disturbance in the DNA sequence and leads to apoptosis (Knizhnik et al. 2013). MGMT is a DNA repair enzyme, which reverses alkylation at the $\mathrm{O} 6$ position of guanine, resulting in removal of alkylating adducts and counteracting the pro-apoptotic effect induced by TMZ (Almalki et al. 2017). The anti-tumour efficacy of TMZ is limited by high levels of MGMT activity as this is thought to offset alkylator modification of tumour DNA (Bello et al. 2006). MGMT assessment by immunohistochemistry and its inverse relationship with therapeutic responsiveness has been proposed by Kovacs et al. and McCormack et al., who suggested that low MGMT expression conferred a better response to therapy compared with cases of high MGMT expression, which showed resistance (Kovacs et al. 2007, 2008, Almalki et al. 2017, McCormack et al. 2018).
Nevertheless, there is considerable overlap between responders and non-responders in terms of MGMT staining, and the techniques of assessment of MGMT are highly variable. It therefore would be unwise to rely on such a factor to decide on the use of TMZ in any specific case.

Another factor affecting the anti-tumour efficacy of TMZ is the mismatch repair pathway (MMR). It is involved in the removal of DNA base mismatches caused either by DNA replication errors or through DNA damage. Mutations in the genes involved in that pathway (e.g. MSH2, MLH1, PMS2 and MSH6) play important roles in the tumour response to therapy. MMR mediates reaction to certain forms of DNA damage-inducing agents that can modify the structure of bases, including alkylating agents such as TMZ. MMR-deficient cells are resistant to chemotherapy due to suppression of the cell cycle and apoptotic responses to these compounds. Negative MSH6 staining is related to resistance to TMZ therapy with continued tumour growth (summarised by Martin et al. 2010).

Based on the currently available evidence, the ESE guidelines suggest that TZM monotherapy should be the first-line chemotherapy after failure of standard therapies (R3.4.1, ++00) (generally, $150-200 \mathrm{mg} / \mathrm{m}^{2}$ for 5 consecutive days every 28 days, R3.4.3, +000). The response should be assessed after initial three cycles of therapy (R3.4.2, ++00), with treatment continuation for at least 6 months in total but only in responder patients (R3.4.7, +000) (Raverot et al. 2018a) (Fig. 3). Since the MGMT status carries a predictive value of the response to TZM, its immunohistochemical evaluation by an expert neuropathologist is needed, and high MGMT expression is suggestive of a lack of response; however, there may be exceptions R 3.4.6 (++00) (Raverot et al. 2018a), and we personally would not rely on this in making therapeutic decisions.

TMZ therapy requires careful clinical observation for potential adverse effects and monitoring of haematological parameters and liver function tests (R3.4.4, +++0$)$. In the 


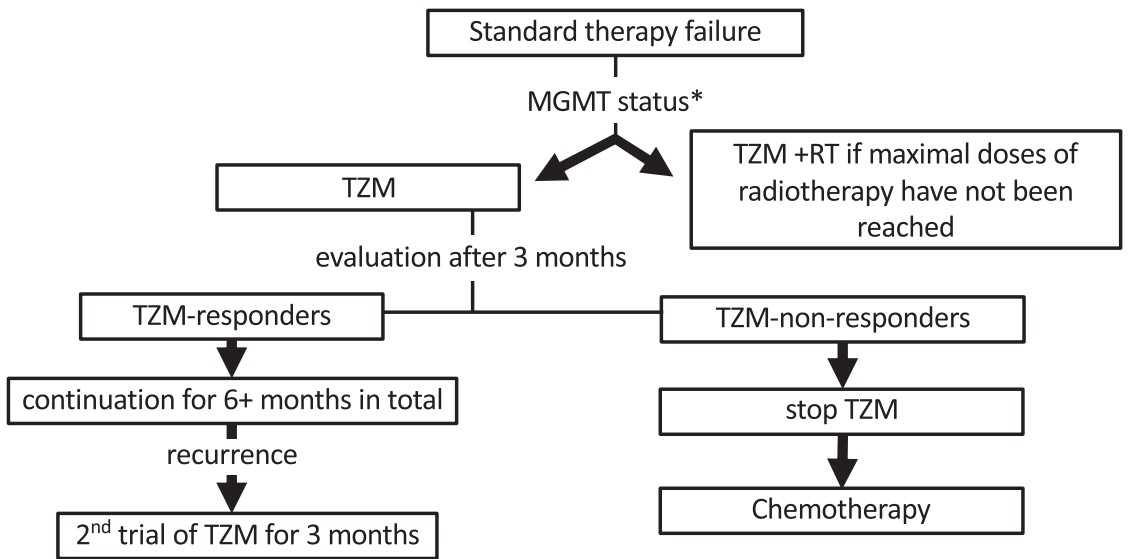

Figure 3

Therapeutic algorithm for APT and PC after failure of standard medical treatment with maximally tolerated doses in order to control tumour growth as per ESE guidance. MGMT status* - ESE suggests that evaluation of MGMT status by immunohistochemistry by an expert neuropathologist should be performed. High MGMT expression is suggestive of a lack of response; however, there may be exceptions $((++00)$ R 3.4.6) (Raverot et al. 2018a,b). group of patients with rapid tumour growth in whom maximal doses of radiotherapy have not been reached, combining TMZ and radiotherapy might be beneficial (R3.4.5, +000) (Raverot et al. 2018a).

A recent survey by McCormack et al. confirmed the role of TMZ as first-line chemotherapeutic treatment of aggressive pituitary tumours and carcinomas. This survey provided further information on predictive markers of response to $\mathrm{TMZ}$ including hormonal activity, low MGMT and concurrent radiotherapy, all associated with a better response. The data from an electronic survey to ESE members (Dec 2015-Nov 2016) included 40 PCs, 125 aggressive tumours and 1 unclassified case, with a median age at diagnosis of 43 (range 4-79) years. In that cohort 69\% of the tumours were hormonally active, with corticotrophs being the most frequent functioning subtype (45\%). The Ki-67 index did not distinguish aggressive tumours from carcinomas. TMZ as a first-line chemotherapy was used in $157 / 166$ patients, resulting in $6,31,33$ and $30 \%$ of radiological complete responses (CRs), partial responses $(\mathrm{PR})$, stable disease (SD) and progressive disease (PD), respectively, at the end of the treatment (median nine cycles). Patients receiving concomitant radiotherapy and TMZ responded more frequently in general, whereas CRs were seen only in patients with low MGMT expression. Interestingly, hormonally active tumours were more likely to respond to TMZ than non-functioning ones, independent of MGMT status. Of patients with CR, PR and SD, 25, 40 and 48\% respectively progressed after a median of 12-month follow-up (McCormack et al. 2018). However, despite encouraging initial results, TMZ treatment appears to be effective in only about half of the patients and does not provide long-term control of aggressive tumours (Lasolle \& Raverot 2016, Losa et al. 2016, Halevy \& Whitelaw 2017). The poor efficacy of other drugs highlights the need to identify additional effective therapies (McCormack et al. 2018).

\section{Alternative treatments for TZM-resistant pituitary tumours}

TheESEguidelines make recommendations for patients who either did not respond to TZM treatment or subsequently recurred. In the group of patients who recurred following response to TZM, a second trial of three cycles could be a therapeutic option R 3.4 .9 (+000). In patients with rapid tumour progression on TZM, a trial with other systemic cytotoxic therapy should be considered. Given the variety of chemotherapeutic agents that have been reported, the experts were unable to suggest a particular regimen R3.4.8 (+000). Historical pre-TZM papers reported that the combination of lomustine/5-fluorouracil proved easy to administer with minimal toxicity, although the response rate was only 14\% (Kaltsas et al. 1998).

In patients with isolated metastases, a consideration of loco-regional therapies should be made, regardless of discussions on systemic treatment R 3.5.1 (+000) (Raverot et al. 2018a).

Some case reports suggested that other chemotherapeutic agents might be useful in combination with TMZ. Thearle et al. reported a case with an aggressive ACTH-oma treated with TMZ and capecitabine. In this case, although the tumour decreased remarkably in size and serum ACTH levels, it recurred after 5 months, transforming to a more malignant phenotype (Thearle et al. 2011).

Somatostatin receptors (types 1, 5 and 2) are widely expressed in different pituitary tumour subtypes (Cakir et al. 2010a,b). Bode et al. reported a case with a widespread intracranial and systemic metastatic ACTH-secreting PC treated with TMZ and pasireotide who demonstrated tumour control for 12 months in combination with TMZ, 
and for a subsequent 9 months on monotherapy with pasireotide (Bode et al. 2010).

Pituitary uptake of ${ }^{68} \mathrm{Ga}$-DOTATATE or other radiolabelled somatostatin analogues has been shown to be elevated on PET/CT scanning (Xiao et al. 2015), suggesting that peptide receptor radionuclide therapy (PRRT) could be an alternative option for pituitary tumours resistant to TZM (Goglia et al. 2008). However, very few patients are reported in the literature. A giant prolactinoma resistant to dopamine agonists, radiotherapy and somatostatin analogues was treated with ${ }^{111}$ In-DTPA-octreotide and achieved an over 50\% reduction in tumour size, maintained for 2 years (Baldari et al. 2012). Maclean et al. reported on three patients, one with a non-functioning pituitary carcinoma, one with a silent corticotroph tumour and one with a mixed $\mathrm{GH}-$ and prolactin-secreting tumour, all treated with ${ }^{177} \mathrm{Lu}$-DOTATATE. Only the non-functioning pituitary carcinoma showed SD for 40 months, the remaining two rapidly progressing to death (Maclean et al. 2014).

PI3K/Akt/mTOR signalling is upregulated in pituitary tumours (Dworakowska et al. 2009b), and the anti-proliferative effect of mTOR inhibitor, everolimus (on pituitary cell lines or primary cultures), has been demonstrated in vitro (Cerovac et al. 2010). Jouanneau et al. reported an ACTH-secreting PC treated with the combination of everolimus and octreotide: this combined therapy, however, neither controlled tumour growth nor ACTH secretion (Jouanneau et al. 2012).

The epidermal growth factor receptor (EGFR), which activates MAPK and AKT pathways, stimulates cell growth and hormone production in prolactin, GH and ACTHsecreting tumours in vivo and in vitro. Lapatinib, a dual HER2/EGFR inhibitor, and gefitinib, a more specific EGFR inhibitor, were shown to have anti-proliferative effects in vitro (Fukuoka et al. 2011a,b). Two resistant macroprolactinomas patients were treated with lapatinib for a 6 months, showing in a first case a $78 \%$ of reduction in prolactin levels and a $22 \%$ decrease in tumour size, whereas in the second case a $42 \%$ of reduction in prolactin levels was observed and the tumour size remained unchanged (Cooper et al. 2014). A clinical trial is currently underway to validate these encouraging results in a larger cohort of patient with non-functioning tumours after recurring after resection, in patients with prolactinomas resistant to dopamine agonist therapy, and in patients with recurrent Cushing's disease (NCT00939523; https://clinicaltrials. gov/ct2/show/ NCT00939523) (Lasolle \& Raverot 2016).

Anti-angiogenic therapy was attempted in the treatment of malignant pituitary tumours. Ortiz et al. reported a case with an aggressive silent corticotroph tumour, progressing to a carcinoma after TMZ. Antivascular endothelial growth factor (bevacizumab) therapy was introduced, and a control of the tumour was achieved for 26 months (Ortiz et al. 2012). We have recently treated a patient with a progressive metastatic corticotroph tumour with capecitabine, lomustine and bevacizumab, with SD for nearly 6 months, but he then succumbed to an infective illness (unpublished data).

Programmed death 1 (PD-1) blockade has shown durable objective responses in a variety of malignancies, and the key predictive markers for this immunotherapy were PD-L1 and CD8+ tumour-infiltrating lymphocyte (TILs) expression. A recent study by Wang et al. reported that PD-L1 was frequently expressed in functioning PAs with aggressive behaviour; immunotherapy could thus be a promising treatment option for aggressive pituitary tumours. One hundred and ninety one patients with PAs were retrospectively involved in this study, consisting of 106 non-functioning adenomas (NFPAs, 55.5\%), 40 prolactinomas (20.9\%), $31 \mathrm{GH}$-secreting tumours (16.2\%), 9 corticotrophinomas (4.7\%) and five pluri-hormonal adenomas (2.6\%) respectively: $36.6 \%$ of them were PD-L1 positive and $86.9 \%$ were CD8+ TILs positive. Positive PD-L1 immunostaining presented more frequently in functioning tumours $(58.8 \%)$ compared with the nonfunctioning group $(34.3 \%, P=0.000)$. Moreover, the rates of PD-L1 expression were more associated with increased blood levels of prolactin, GH, ACTH and cortisol. In contrast, positive CD8+ TILs immunostaining only correlated with elevated blood level of GH. For the analysis of immune markers with pathological results, PD-L1 expression was associated with prolactin and GH immunostaining and a higher Ki-67 index, while CD8+ TILs was only correlated with prolactin immunostaining (Wang et al. 2018).

\section{Summary}

Recent changes to the WHO classification of pituitary tumours and new ESE guidelines have clarified our assessment of pituitary tumours in general, and 'aggressive tumours' in particular. There is an increasing move to consider all such tumours to be a variant of generic neuroendocrine tumours, and thus, to have at least some malignant potential. There is no specific histopathological marker of such potential, although the Ki-67 index is useful, and the dividing line between an aggressive tumour and a carcinoma is blurred. Furthermore, there appears to be a spectrum 
of functionality from those tumours which are truly non-functioning to those which are highly secretory. Thus, radiological, surgical and clinical factors all need to be taken into account in addition to pathology when considering the optimal therapeutic strategy and its sequencing. Surgery (usually trans-sphenoidal), radiotherapy (in its various guises), and more recently temozolomide, may all play a role, but for the future a more precise understanding of tumorigenesis may help us customise individual treatments and employ more specifically targeted therapies for the most aggressive of tumours. For the time being, it is fortunate that the majority of pituitary tumours remain benign and are readily controllable.

\section{Declaration of interest}

The authors declare that there is no conflict of interest that could be perceived as prejudicing the impartiality of this review.

\section{Funding}

This work did not receive any specific grant from any funding agency in the public, commercial or not-for-profit sector

\section{Author contribution statement}

Each co-author contributed to the manuscript equally.

\section{Acknowledgements}

Dr D Dworakowska was supported by Foundation for Polish Science within a programme BRIDGE, which was co-financed by the EU within 7th FP.

\section{References}

Alexandraki KI, Munayem Khan M, Chahal HS, Dalantaeva NS, Trivellin G, Berney DM, Caron P, Popovic V, Pfeifer M, Jordan S, et al. 2012 Oncogene-induced senescence in pituitary adenomas and carcinomas. Hormones 11 297-307. (https://doi.org/10.14310/ horm.2002.1358)

Almalki MH, Aljoaib NN, Alotaibi MJ, Aldabas BS, Wahedi TS, Ahmad MH \& Alshahrani F 2017 Temozolomide therapy for resistant prolactin-secreting pituitary adenomas and carcinomas: a systematic review. Hormones 16 139-149.

Asa SL, Casar-Borota O, Chanson P, Delgrange E, Earls P, Ezzat S, Grossman A, Ikeda H, Inoshita N, Karavitaki N, et al. 2017 From pituitary adenoma to pituitary neuroendocrine tumor (PitNET): an International Pituitary Pathology Club proposal. Endocrine-Related Cancer 24 C5-C8. (https://doi.org/10.1530/ERC-17-0004)

Baldari S, Ferrau F, Alafaci C, Herberg A, Granata F, Militano V, Salpietro FM, Trimarchi F \& Cannavo S 2012 First demonstration of the effectiveness of peptide receptor radionuclide therapy (PRRT) with 111In-DTPA-octreotide in a giant PRL-secreting pituitary adenoma resistant to conventional treatment. Pituitary $\mathbf{1 5}$ (Supplement 1) S57-S60. (https://doi.org/10.1007/s11102-011-0373-5)
Bello MJ, De Campos JM, Isla A, Casartelli C \& Rey JA 2006 Promoter CpG methylation of multiple genes in pituitary adenomas: frequent involvement of caspase-8. Oncology Reports 15 443-448.

Bode H, Seiz M, Lammert A, Brockmann MA, Back W, Hammes HP \& Thome C 2010 SOM230 (pasireotide) and temozolomide achieve sustained control of tumour progression and ACTH secretion in pituitary carcinoma with widespread metastases. Experimental and Clinical Endocrinology and Diabetes 118 760-763. (https://doi. org/10.1055/s-0030-1253419)

Burger PC, Shibata T \& Kleihues P 1986 The use of the monoclonal antibody Ki-67 in the identification of proliferating cells: application to surgical neuropathology. American Journal of Surgical Pathology 10 611-617. (https://doi.org/10.1097/00000478198609000-00003)

Cakir M, Dworakowska D \& Grossman A 2010a Somatostatin receptor biology in neuroendocrine and pituitary tumours: part 1 - molecular pathways. Journal of Cellular and Molecular Medicine 14 2570-2584. (https://doi.org/10.1111/j.1582-4934.2010.01125.x)

Cakir M, Dworakowska D \& Grossman A $2010 b$ Somatostatin receptor biology in neuroendocrine and pituitary tumours: part 2 - clinical implications. Journal of Cellular and Molecular Medicine 14 2585-2591. (https://doi.org/10.1111/j.1582-4934.2010.01125_1.x)

Casson IF, Walker BA, Hipkin LJ, Davis JC, Buxton PH \& Jeffreys RV 1986 An intrasellar pituitary tumour producing metastases in liver, bone and lymph glands and demonstration of ACTH in the metastatic deposits. Acta Endocrinologica $111300-304$.

Ceccato F, Regazzo D, Barbot M, Denaro L, Emanuelli E, Borsetto D, Rolma G, Alessio L, Gardiman MP, Lombardi G, et al. 2018 Early recognition of aggressive pituitary adenomas: a single-centre experience. Acta Neurochirurgica 160 49-55. (https://doi.org/10.1007/ s00701-017-3396-5)

Cerovac V, Monteserin-Garcia J, Rubinfeld H, Buchfelder M, Losa M, Florio T, Paez-Pereda M, Stalla GK \& Theodoropoulou M 2010 The somatostatin analogue octreotide confers sensitivity to rapamycin treatment on pituitary tumor cells. Cancer Research 70 666-674. (https://doi.org/10.1158/0008-5472.CAN-09-2951)

Colao A, Grasso LF, Pivonello R \& Lombardi G 2011 Therapy of aggressive pituitary tumors. Expert Opinion on Pharmacotherapy 12 1561-1570. (https://doi.org/10.1517/14656566.2011.568478)

Cooper O 2015 Silent corticotroph adenomas. Pituitary 18 225-231. (https://doi.org/10.1007/s11102-014-0624-3)

Cooper O, Mamelak A, Bannykh S, Carmichael J, Bonert V, Lim S, CookWiens G \& Ben-Shlomo A 2014 Prolactinoma ErbB receptor expression and targeted therapy for aggressive tumors. Endocrine $\mathbf{4 6}$ 318-327. (https://doi.org/10.1007/s12020-013-0093-x)

Cuylen S, Blaukopf C, Politi AZ, Muller-Reichert T, Neumann B, Poser I, Ellenberg J, Hyman AA \& Gerlich DW 2016 Ki-67 acts as a biological surfactant to disperse mitotic chromosomes. Nature 535 308-312. (https://doi.org/10.1038/nature18610)

Dai C, Feng M, Liu X, Ma S, Sun B, Bao X, Yao Y, Deng K, Wang Y, Xing B, et al. 2016 Refractory pituitary adenoma: a novel classification for pituitary tumors. Oncotarget 7 83657-83668.

Denes J, Swords F, Rattenberry E, Stals K, Owens M, Cranston T, Xekouki P, Moran L, Kumar A, Wassif C, et al. 2015 Heterogeneous genetic background of the association of pheochromocytoma/ paraganglioma and pituitary adenoma: results from a large patient cohort. Journal of Clinical Endocrinology and Metabolism 100 E531-E541. (https://doi.org/10.1210/jc.2014-3399)

Di Ieva A, Rotondo F, Syro LV, Cusimano MD \& Kovacs K 2014 Aggressive pituitary adenomas - diagnosis and emerging treatments Nature Reviews Endocrinology 10 423-435. (https://doi.org/10.1038/ nrendo.2014.64)

Drummond J, Roncaroli, F, Grossman, AB \& Korbonits, M 2018 Clinical and pathological aspects of silent pituitary adenomas. Journal of Clinical Endocrinology and Metabolism [epub]. (https://doi. org/10.1210/jc.2018-00688) 
Dworakowska D \& Grossman AB 2009 The pathophysiology of pituitary adenomas. Best Practice and Research: Clinical Endocrinology and Metabolism 23 525-541. (https://doi.org/10.1016/j.beem.2009.05.004)

Dworakowska D \& Grossman AB 2012 The molecular pathogenesis of pituitary tumors: implications for clinical management. Minerva Endocrinologica 37 157-172.

Dworakowska D, Jassem E, Jassem J, Karmolinski A, Lapinski M, Tomaszewski D, Rzyman W, Jaskiewicz K, Sworczak K \& Grossman AB 2009a Prognostic value of the apoptotic index analysed jointly with selected cell cycle regulators and proliferation markers in non-small cell lung cancer. Lung Cancer 66 127-133. (https://doi.org/10.1016/j.lungcan.2009.01.008)

Dworakowska D, Wlodek E, Leontiou CA, Igreja S, Cakir M, Teng M, Prodromou N, Goth MI, Grozinsky-Glasberg S, Gueorguiev M, et al. $2009 b$ Activation of RAF/MEK/ERK and PI3K/AKT/mTOR pathways in pituitary adenomas and their effects on downstream effectors. Endocrine-Related Cancer 16 1329-1338. (https://doi.org/10.1677/ERC09-0101)

Endo T, Ogawa Y, Watanabe M \& Tominaga T 2018 A case of pituitary carcinoma initially diagnosed as an ectopic growth hormone producing pituitary adenoma with a high Ki-67 labeling index. Journal of Neurological Surgery 79 90-95.

Fukuoka H, Cooper O, Ben-Shlomo A, Mamelak A, Ren SG, Bruyette D \& Melmed S 2011a EGFR as a therapeutic target for human, canine, and mouse ACTH-secreting pituitary adenomas. Journal of Clinical Investigation 121 4712-4721. (https://doi.org/10.1172/JCI60417)

Fukuoka H, Cooper O, Mizutani J, Tong Y, Ren SG, Bannykh S \& Melmed S 2011b HER2/ErbB2 receptor signaling in rat and human prolactinoma cells: strategy for targeted prolactinoma therapy. Molecular Endocrinology 25 92-103. (https://doi.org/10.1210/me.20100353)

George DH, Scheithauer BW, Kovacs K, Horvath E, Young WF Jr, Lloyd RV \& Meyer FB 2003 Crooke's cell adenoma of the pituitary: an aggressive variant of corticotroph adenoma. American Journal of Surgical Pathology 27 1330-1336. (https://doi.org/10.1097/00000478200310000-00005)

Gill AJ, Toon CW, Clarkson A, Sioson L, Chou A, Winship I, Robinson BG, Benn DE, Clifton-Bligh RJ \& Dwight T 2014 Succinate dehydrogenase deficiency is rare in pituitary adenomas. American Journal of Surgical Pathology 38 560-566. (https://doi.org/10.1097/ PAS.0000000000000149)

Goglia U, Ferone D, Sidoti M, Spaziante R, Dadati P, Ravetti JL, Villa G, Bodei L, Paganelli G, Minuto F, et al. 2008 Treatment of a pituitary metastasis from a neuroendocrine tumour: case report and literature review. Pituitary 11 93-102. (https://doi.org/10.1007/s11102-0070038-6)

Gordon MV, Varma D, McLean CA, Bittar RG, Burgess JR \& Topliss DJ 2007 Metastatic prolactinoma presenting as a cervical spinal cord tumour in multiple endocrine neoplasia type one (MEN-1). Clinical Endocrinology 66 150-152.

Gurlek A, Karavitaki N, Ansorge O \& Wass JA 2007 What are the markers of aggressiveness in prolactinomas? Changes in cell biology, extracellular matrix components, angiogenesis and genetics. European Journal of Endocrinology 156 143-153. (https://doi. org/10.1530/eje.1.02339)

Halevy C \& Whitelaw BC 2017 How effective is temozolomide for treating pituitary tumours and when should it be used? Pituitary 20 261-266. (https://doi.org/10.1007/s11102-016-0745-y)

Handy J 1969 Transphenoidal microsurgery of the normal and pathological pituitary. Clinical Neurosurgery 16 185-217. (https://doi. org/10.1093/neurosurgery/16.CN_suppl_1.185)

Hansen TM, Batra S, Lim M, Gallia GL, Burger PC, Salvatori R, Wand G, Quinones-Hinojosa A, Kleinberg L \& Redmond KJ 2014 Invasive adenoma and pituitary carcinoma: a SEER database analysis. Neurosurgical Review 37 279-285; discussion 285-276. (https://doi. org/10.1007/s10143-014-0525-y)
Heaney AP 2011 Clinical review: pituitary carcinoma: difficult diagnosis and treatment. Journal of Clinical Endocrinology and Metabolism 96 3649-3660. (https://doi.org/10.1210/jc.2011-2031)

Heaney A 2014 Management of aggressive pituitary adenomas and pituitary carcinomas. Journal of Neuro-Oncology 117 459-468. (https://doi.org/10.1007/s11060-014-1413-6)

Hirohata T, Ishii Y \& Matsuno A 2014 Treatment of pituitary carcinomas and atypical pituitary adenomas: a review. Neurologia MedicoChirurgica 54 966-973. (https://doi.org/10.2176/nmc.ra.2014-0178)

Iversen K 1952 Acromegaly associated with phaeochromocytoma. Acta Medica Scandinavica 142 1-5. (https://doi. org/10.1111/j.0954-6820.1952.tb13837.x)

Jahangiri A, Wagner JR, Pekmezci M, Hiniker A, Chang EF, Kunwar S, Blevins L \& Aghi MK 2013 A comprehensive long-term retrospective analysis of silent corticotrophic adenomas vs hormone-negative adenomas. Neurosurgery 73 8-17; discussion 17-18. (https://doi. org/10.1227/01.neu.0000429858.96652.1e)

Jouanneau E, Wierinckx A, Ducray F, Favrel V, Borson-Chazot F, Honnorat J, Trouillas J \& Raverot G 2012 New targeted therapies in pituitary carcinoma resistant to temozolomide. Pituitary 15 37-43. (https://doi.org/10.1007/s11102-011-0341-0)

Kaltsas GA, Mukherjee JJ, Plowman PN, Monson JP, Grossman AB \& Besser GM 1998 The role of cytotoxic chemotherapy in the management of aggressive and malignant pituitary tumors. Journal of Clinical Endocrinology and Metabolism 83 4233-4238. (https://doi. org/10.1210/jcem.83.12.5300)

Kaltsas GA, Nomikos P, Kontogeorgos G, Buchfelder M \& Grossman AB 2005 Clinical review: diagnosis and management of pituitary carcinomas. Journal of Clinical Endocrinology and Metabolism 90 3089-3099. (https://doi.org/10.1210/jc.2004-2231)

Kemink SA, Wesseling P, Pieters GF, Verhofstad AA, Hermus AR \& Smals AG 1999 Progression of a Nelson's adenoma to pituitary carcinoma; a case report and review of the literature. Journal of Endocrinological Investigation 22 70-75. (https://doi.org/10.1007/ BF03345482)

Kloppel G 2017 Neuroendocrine neoplasms: dichotomy, origin and classifications. Visceral Medicine 33 324-330. (https://doi. org/10.1159/000481390)

Knizhnik AV, Roos WP, Nikolova T, Quiros S, Tomaszowski KH, Christmann M \& Kaina B 2013 Survival and death strategies in glioma cells: autophagy, senescence and apoptosis triggered by a single type of temozolomide-induced DNA damage. PLOS ONE $\mathbf{8}$ e55665. (https://doi.org/10.1371/journal.pone.0055665)

Knosp E, Steiner E, Kitz K \& Matula C 1993 Pituitary adenomas with invasion of the cavernous sinus space: a magnetic resonance imaging classification compared with surgical findings. Neurosurgery 33 610-617; discussion 617-618.

Kovacs K, Horvath E, Syro LV, Uribe H, Penagos LC, Ortiz LD \& Fadul CE 2007 Temozolomide therapy in a man with an aggressive prolactin-secreting pituitary neoplasm: morphological findings. Human Pathology 38 185-189. (https://doi.org/10.1016/j. humpath.2006.07.014)

Kovacs K, Scheithauer BW, Lombardero M, McLendon RE, Syro LV, Uribe H, Ortiz LD \& Penagos LC 2008 MGMT immunoexpression predicts responsiveness of pituitary tumors to temozolomide therapy. Acta Neuropathologica 115 261-262. (https://doi.org/10.1007/s00401007-0279-5)

Krueger EM \& Seibly J 2017 Seeding of a pituitary adenoma or atypical pituitary carcinoma? Cureus 9 e1211.

Langlois F, McCartney S \& Fleseriu M 2017 Recent progress in the medical therapy of pituitary tumors. Endocrinology and Metabolism 32 162-170. (https://doi.org/10.3803/EnM.2017.32.2.162)

Lasolle H \& Raverot G 2016 Therapeutic innovations in endocrine diseases - part 3: temozolomide and future therapeutics for aggressive pituitary tumors and carcinomas. La Presse Médicale $\mathbf{4 5}$ e211-e216. (https://doi.org/10.1016/j.lpm.2016.05.008) 
Lasolle H, Cortet C, Castinetti F, Cloix L, Caron P, Delemer B, Desailloud R, Jublanc C, Lebrun-Frenay C, Sadoul JL, et al. 2017 Temozolomide treatment can improve overall survival in aggressive pituitary tumors and pituitary carcinomas. European Journal of Endocrinology 176 769-777. (https://doi.org/10.1530/EJE-16-0979)

Lenders N \& McCormack A 2018 Malignant transformation in nonfunctioning pituitary adenomas (pituitary carcinoma). Pituitary 21 217-229. (https://doi.org/10.1007/s11102-017-0857-z)

Lopes MBS 2017 The 2017 World Health Organization classification of tumors of the pituitary gland: a summary. Acta Neuropathologica 134 521-535.

Lopes MB, Scheithauer BW \& Schiff D 2005 Pituitary carcinoma: diagnosis and treatment. Endocrine 28 115-121. (https://doi. org/10.1385/ENDO:28:1:115)

Losa M, Bogazzi F, Cannavo S, Ceccato F, Curto L, De Marinis L, Iacovazzo D, Lombardi G, Mantovani G, Mazza E, et al. 2016 Temozolomide therapy in patients with aggressive pituitary adenomas or carcinomas. Journal of Neuro-Oncology 126 519-525. (https://doi.org/10.1007/s11060-015-1991-y)

Lv L, Hu Y, Yin S, Wang M, Zhou P, Zhang N, Ma W, Zhang S \& Jiang S 2018 Clinically aggressive phenotype: a clinicopathological case series of atypical pituitary adenomas. Clinical Neurology and Neurosurgery 167 93-98. (https://doi.org/10.1016/j. clineuro.2018.02.001)

Maclean J, Aldridge M, Bomanji J, Short S \& Fersht N 2014 Peptide receptor radionuclide therapy for aggressive atypical pituitary adenoma/carcinoma: variable clinical response in preliminary evaluation. Pituitary 17 530-538. (https://doi.org/10.1007/s11102013-0540-y)

Manojlovic-Gacic E, Engstrom BE \& Casar-Borota O 2018 Histopathological classification of non-functioning pituitary neuroendocrine tumors. Pituitary 21 119-129. (https://doi. org/10.1007/s11102-017-0855-1)

Martin SA, Lord CJ \& Ashworth A 2010 Therapeutic targeting of the DNA mismatch repair pathway. Clinical Cancer Research 16 5107-5113. (https://doi.org/10.1158/1078-0432.CCR-10-0821)

McCormack A, Dekkers OM, Petersenn S, Popovic V, Trouillas J, Raverot G, Burman P \& collaborators ESEs 2018 Treatment of aggressive pituitary tumours and carcinomas: results of a European Society of Endocrinology (ESE) survey 2016. European Journal of Endocrinology 178 265-276. (https://doi.org/10.1530/EJE-17-0933)

Meij BP, Lopes MB, Ellegala DB, Alden TD \& Laws ER Jr 2002 The longterm significance of microscopic dural invasion in 354 patients with pituitary adenomas treated with transsphenoidal surgery. Journal of Neurosurgery 96 195-208. (https://doi.org/10.3171/ jns.2002.96.2.0195)

Mete O \& Lopes MB 2017 Overview of the 2017 WHO Classification of Pituitary Tumors. Endocrine Pathology 28 228-243. (https://doi. org/10.1007/s12022-017-9498-z)

Mete O, Hayhurst C, Alahmadi H, Monsalves E, Gucer H, Gentili F, Ezzat S, Asa SL \& Zadeh G 2013 The role of mediators of cell invasiveness, motility, and migration in the pathogenesis of silent corticotroph adenomas. Endocrine Pathology 24 191-198. (https://doi org/10.1007/s12022-013-9270-y)

Micko AS, Wohrer A, Wolfsberger S \& Knosp E 2015 Invasion of the cavernous sinus space in pituitary adenomas: endoscopic verification and its correlation with an MRI-based classification. Journal of Neurosurgery 122 803-811. (https://doi.org/10.3171/2014.12. JNS141083)

Minniti G, Traish D, Ashley S, Gonsalves A \& Brada M 2005 Risk of second brain tumor after conservative surgery and radiotherapy for pituitary adenoma: update after an additional 10 years. Journal of Clinical Endocrinology and Metabolism 90 800-804. (https://doi. org/10.1210/jc.2004-1152)

Nishioka H \& Inoshita N 2018 New WHO classification of pituitary adenomas (4th edition): assessment of pituitary transcription factors and the prognostic histological factors. Brain Tumor Pathology 35 57-61. (https://doi.org/10.1007/s10014-017-0307-7)

Ogawa Y, Jokura H, Niizuma K \& Tominaga T 2018 Mid-term prognosis of non-functioning pituitary adenomas with high proliferative potential: really an aggressive variant? Journal of Neuro-Oncology $\mathbf{1 3 7}$ 543-549. (https://doi.org/10.1007/s11060-017-2740-1)

Ortiz LD, Syro LV, Scheithauer BW, Ersen A, Uribe H, Fadul CE, Rotondo F, Horvath E \& Kovacs K 2012 Anti-VEGF therapy in pituitary carcinoma. Pituitary 15 445-449. (https://doi.org/10.1007/ s11102-011-0346-8)

Osamura RY, Lopes MBS, Grossman A, Kontogeorgos G \& Trouillas J 2017 a Introduction. In WHO Classification of Tumours of Endocrine Organs, 4th ed. Eds RV Lloyd, RY Osamura, G Klöppel \& J Rosai. Lyon, France: IARC Press.

Osamura RY, Lopes MBS, Grossman A, Matsuno A, Korbonits M, Trouillas J \& Kovacs K 2017b Pituitary adenoma. In WHO Classification of Tumours of Endocrine Organs, 4th ed., pp 14-18. Eds RV Lloyd, RY Osamura, G Klöppel \& J Rosai. Lyon, France: IARC Press.

Ozer E, Canda MS, Ulukus C, Guray M \& Erbayraktar S 2003 Expression of Bcl-2, Bax and p53 proteins in pituitary adenomas: an immunohistochemical study. Tumori 89 54-59. (https://doi. org/10.1177/030089160308900112)

Panzuto F, Cicchese N, Partelli S, Rinzivillo M, Capurso G, Merola E, Manzoni M, Pucci E, Iannicelli E, Pilozzi E, et al. 2017 Impact of Ki67 re-assessment at time of disease progression in patients with pancreatic neuroendocrine neoplasms. PLOS ONE 12 e0179445. (https://doi.org/10.1371/journal.pone.0179445)

Pei L, Melmed S, Scheithauer B, Kovacs K \& Prager D 1994 H-ras mutations in human pituitary carcinoma metastases. Journal of Clinical Endocrinology and Metabolism 78 842-846.

Pernicone PJ, Scheithauer BW, Sebo TJ, Kovacs KT, Horvath E, Young WF Jr, Lloyd RV, Davis DH, Guthrie BL \& Schoene WC 1997 Pituitary carcinoma: a clinicopathologic study of 15 cases. Cancer 79 804-812. (https://doi.org/10.1002/(SICI)1097-0142(19970215)79:4<804::AIDCNCR18>3.0.CO;2-3)

Petterson T, MacFarlane IA, MacKenzie JM \& Shaw MD 1992 Prolactin secreting pituitary carcinoma. Journal of Neurology, Neurosurgery, and Psychiatry 55 1205-1206. (https://doi.org/10.1136/jnnp.55.12.1205)

Priola SM, Esposito F, Cannavo S, Conti A, Abbritti RV, Barresi V, Baldari S, Ferrau F, Germano A, Tomasello F, et al. 2017 Aggressive pituitary adenomas: the dark side of the moon. World Neurosurgery 97 140-155. (https://doi.org/10.1016/j.wneu.2016.09.092)

Ragel BT \& Couldwell WT 2004 Pituitary carcinoma: a review of the literature. Neurosurgical Focus 16 E7.

Ramirez C, Cheng S, Vargas G, Asa SL, Ezzat S, Gonzalez B, Cabrera L, Guinto G \& Mercado M 2012 Expression of Ki-67, PTTG1, FGFR4, and SSTR 2, 3, and 5 in nonfunctioning pituitary adenomas: a high throughput TMA, immunohistochemical study. Journal of Clinical Endocrinology and Metabolism 97 1745-1751. (https://doi. org/10.1210/jc.2011-3163)

Raverot G, Dantony E, Beauvy J, Vasiljevic A, Mikolasek S, BorsonChazot F, Jouanneau E, Roy P \& Trouillas J 2017 Risk of recurrence in pituitary neuroendocrine tumors: a prospective study using a fivetiered classification. Journal of Clinical Endocrinology and Metabolism 102 3368-3374. (https://doi.org/10.1210/jc.2017-00773)

Raverot G, Burman P, McCormack A, Heaney A, Petersenn S, Popovic V, Trouillas J, Dekkers OM \& European Society of E 2018a European Society of Endocrinology Clinical Practice Guidelines for the management of aggressive pituitary tumours and carcinomas. European Journal of Endocrinology 178 G1-G24. (https://doi. org/10.1530/EJE-17-0796)

Raverot G, Vasiljevic A \& Jouanneau E $2018 b$ Prognostic factors of regrowth in nonfunctioning pituitary tumors. Pituitary 21 176-182. (https://doi.org/10.1007/s11102-017-0861-3)

Richardson TE, Shen ZJ, Kanchwala M, Xing C, Filatenkov A, Shang P, Barnett S, Abedin Z, Malter JS, Raisanen JM, et al. 2017 Aggressive
(C) 2018 Society for Endocrinology Published by Bioscientifica Ltd. Printed in Great Britain 
behavior in silent subtype III pituitary adenomas may depend on suppression of local immune response: a whole transcriptome analysis. Journal of Neuropathology and Experimental Neurology $\mathbf{7 6}$ 874-882. (https://doi.org/10.1093/inen/nlx072)

Robertson AM \& Heaney AP 2016 Molecular markers in pituitary tumors. Current Opinion in Endocrinology, Diabetes and Obesity 23 324-330. (https://doi.org/10.1097/MED.0000000000000266)

Salehi F, Agur A, Scheithauer BW, Kovacs K, Lloyd RV \& Cusimano M 2009 Ki-67 in pituitary neoplasms: a review - part I. Neurosurgery 65 429-437; discussion 437. (https://doi.org/10.1227/01. NEU.0000349930.66434.82)

Sav A, Rotondo F, Syro LV, Di Ieva A, Cusimano MD \& Kovacs K 2015 Invasive, atypical and aggressive pituitary adenomas and carcinomas. Endocrinology and Metabolism Clinics of North America 44 99-104. (https://doi.org/10.1016/j.ecl.2014.10.008)

Sbardella E, Farah G, Fathelrahman A, Cudlip S, Ansorge O, Karavitaki N \& Grossman AB 2016 A macroprolactinoma becoming resistant to cabergoline and developing atypical pathology. Endocrinology, Diabetes and Metabolism Case Reports 2016 16-0038.

Scheithauer BW, Kurtkaya-Yapicier O, Kovacs KT, Young WF Jr \& Lloyd RV 2005 Pituitary carcinoma: a clinicopathological review. Neurosurgery 56 1066-1074; discussion 1066-1074.

Scheithauer BW, Kovacs K, Nose V, Lombardero M, Osamura YR, Lloyd RV, Horvath E, Pagenstecher A, Bohl JE \& Tews DS 2009 Multiple endocrine neoplasia type 1-associated thyrotropinproducing pituitary carcinoma: report of a probable de novo example. Human Pathology 40 270-278. (https://doi.org/10.1016/j. humpath.2008.06.013)

Stewart PM, Carey MP, Graham CT, Wright AD \& London DR 1992 Growth hormone secreting pituitary carcinoma: a case report and literature review. Clinical Endocrinology 37 189-194. (https://doi. org/10.1111/j.1365-2265.1992.tb02306.x)

Suliman M, Royds J, Cullen D, Timperley W, Powell T, Battersby R \& Jones TH $2001 \mathrm{Mdm} 2$ and the p53 pathway in human pituitary adenomas. Clinical Endocrinology 54 317-325. (https://doi. org/10.1046/j.1365-2265.2001.01195.x)

Syro LV, Rotondo F, Ortiz LD \& Kovacs K 2018 Treatment of pituitary tumors with temozolomide: an update. Endocrine-Related Cancer $\mathbf{2 5}$ T159-T169. (https://doi.org/10.1530/ERC-18-0015)

Tampourlou M, Ntali G, Ahmed S, Arlt W, Ayuk J, Byrne JV, Chavda S, Cudlip S, Gittoes N, Grossman A, et al. 2017 Outcome of nonfunctioning pituitary adenomas that regrow after primary treatment: a study from two large UK centers. Journal of Clinical Endocrinology and Metabolism 102 1889-1897. (https://doi. org/10.1210/jc.2016-4061)

Tanaka T, Kato N, Aoki K, Watanabe M, Arai T, Hasegawa Y \& Abe T 2013 Long-term follow-up of growth hormone-producing pituitary carcinoma with multiple spinal metastases following multiple surgeries: case report. Neurologia Medico-Chirurgica 53 707-711. (https://doi.org/10.2176/nmc.cr2012-0152)

Taya K, Terao T, Nakazaki H, Sawauchi S, Numoto RT, Murakami S, Yamaguchi Y, Hashimoto T \& Abe T 2004 Intracranial metastasis of pituitary adenoma: a case report. No Shinkei Geka 32 279-284.

Taylor WA, Uttley D \& Wilkins PR 1994 Multiple dural metastases from a pituitary adenoma. Case report. Journal of Neurosurgery 81 624-626. (https://doi.org/10.3171/jns.1994.81.4.0624)

Thapar K, Kovacs K, Scheithauer BW, Stefaneanu L, Horvath E, Pernicone PJ, Murray D \& Laws ER Jr 1996a Proliferative activity and invasiveness among pituitary adenomas and carcinomas: an analysis using the MIB-1 antibody. Neurosurgery 38 99-106; discussion 106107. (https://doi.org/10.1097/00006123-199601000-00024)

Thapar K, Scheithauer BW, Kovacs K, Pernicone PJ \& Laws ER Jr 1996b p53 expression in pituitary adenomas and carcinomas: correlation with invasiveness and tumor growth fractions. Neurosurgery $\mathbf{3 8}$ 765-770; discussion 770-761. (https://doi.org/10.1227/00006123199604000-00027)

Thearle MS, Freda PU, Bruce JN, Isaacson SR, Lee Y \& Fine RL 2011 Temozolomide (Temodar $(\mathrm{R}))$ and capecitabine (Xeloda(R)) treatment of an aggressive corticotroph pituitary tumor. Pituitary 14 418-424. (https://doi.org/10.1007/s11102-009-0211-1)

Trouillas J, Roy P, Sturm N, Dantony E, Cortet-Rudelli C, Viennet G, Bonneville JF, Assaker R, Auger C, Brue T, et al. 2013 A new prognostic clinicopathological classification of pituitary adenomas: a multicentric case-control study of 410 patients with 8 years postoperative follow-up. Acta Neuropathologica 126 123-135. (https://doi. org/10.1007/s00401-013-1084-y)

Trouillas J, Burman P, McCormack AI, Petersenn S, Popovic V, Dekkers O \& Raverot G 2018 Aggressive pituitary tumours and carcinomas: two sides of the same coin? European Journal of Endocrinology 178 C7-C9. (https://doi.org/10.1530/EJE-18-0250)

Tufton N, Roncaroli F, Hadjidemetriou I, Dang MN, Denes J, Guasti L, Thom M, Powell M, Baldeweg SE, Fersht N, et al. 2017 Pituitary carcinoma in a patient with an SDHB mutation. Endocrine Pathology 28 320-325. (https://doi.org/10.1007/s12022-017-9474-7)

Wang PF, Wang TJ, Yang YK, Yao K, Li Z, Li YM \& Yan CX 2018 The expression profile of PD-L1 and CD8(+) lymphocyte in pituitary adenomas indicating for immunotherapy. Journal of Neuro-Oncology 139 89-95. (https://doi.org/10.1007/s11060-018-2844-2)

Webb KM, Laurent JJ, Okonkwo DO, Lopes MB, Vance ML \& Laws ER Jr 2003 Clinical characteristics of silent corticotrophic adenomas and creation of an internet-accessible database to facilitate their multiinstitutional study. Neurosurgery 53 1076-1084; discussion 10841075. (https://doi.org/10.1227/01.NEU.0000088660.16904.F7)

Wierinckx A, Roche M, Legras-Lachuer C, Trouillas J, Raverot G \& Lachuer J 2017 MicroRNAs in pituitary tumors. Molecular and Cellular Endocrinology 456 51-61. (https://doi.org/10.1016/j.mce.2017.01.021)

Xiao J, Zhu Z, Zhong D, Ma W \& Wang R 2015 Improvement in diagnosis of metastatic pituitary carcinoma by 68Ga DOTATATE PET/ CT. Clinical Nuclear Medicine 40 e129-e131. (https://doi.org/10.1097/ RLU.0000000000000462)

Xu Z, Ellis S, Lee CC, Starke RM, Schlesinger D, Lee Vance M, Lopes MB \& Sheehan J 2014 Silent corticotroph adenomas after stereotactic radiosurgery: a case-control study. International Journal of Radiation Oncology, Biology, Physics 90 903-910. (https://doi.org/10.1016/j. ijrobp.2014.07.013)

Yang Z, Zhang T \& Gao H 2016 Genetic aspects of pituitary carcinoma: a systematic review. Medicine 95 e5268. (https://doi.org/10.1097/ MD.0000000000005268)

Yoo F, Kuan EC, Heaney AP, Bergsneider M \& Wang MB 2018 Corticotrophic pituitary carcinoma with cervical metastases: case series and literature review. Pituitary 21 290-301. (https://doi. org/10.1007/s11102-018-0872-8)

Zaidi HA, Cote DJ, Dunn IF \& Laws ER Jr 2016 Predictors of aggressive clinical phenotype among immunohistochemically confirmed atypical adenomas. Journal of Clinical Neuroscience 34 246-251. (https://doi.org/10.1016/j.jocn.2016.09.014)

Received in final form 27 June 2018

Accepted 9 July 2018

Accepted Preprint published online 9 July 2018 (c) 2018 Society for Endocrinology Published by Bioscientifica Ltd. Printed in Great Britain 